Bulletin de la Société Royale des Sciences de Liège, Vol. 86, special issue, 2017, p. 182 - 188

\title{
Synthesis of Cobalt nanoparticles by Complex Demolition Method Using the Reaction between Organic Ligand Schiff base and Cobalt Chloride by Ultrasonication
}

\author{
Seyed Jalal HoseYni ${ }^{1}$, Mahboobe MANOOCHEHRI ${ }^{1 *}$, Maryam Daghighi ASLI ${ }^{1}$ \\ ${ }^{1}$ Departman of Chemistry, Central Tehran Branch, Islamic Azad University Tehran-Iran
}

\begin{abstract}
The present article deals with the formation of cobalt nanoparticle from cobalt (II) chloride salt and Schiff base ligand derived from para-chloro-aniline and 3-nitro benzaldehyde. Through the method, instead of using the sol-gel or thermal degradation methods, ultrasound device is used to synthesize the existing nanoparticles. During ligand synthesis method to ensure the formation of Schiff base ligand, IR-profile Jasco4200FT-IR spectrometer was used in the contexts of $\mathrm{KBr}$ tablets. Finally, to ensure the formation of nanoparticles, EM32000 electron scanner microscope was used.
\end{abstract}

Keywords: Cobalt Nanoparticles, Complex Demolition Method, Ligand Schiff, Ultrasonic Technology

\section{Introduction}

Cobalt is a metal that has many applications as catalyst and anti-bacterial compounds and so on. Today, this metal is used so much in nanoscales. Through recent years, the synthesis of metal nanoparticles has been vigilantly considered. This is due to their peculiar properties and potential applications in different fields like optical, electronic, catalytic, magnetic materials and the rest.[1-7] Synthesis of metallic nanoparticles using wet chemistry is a mainly effective path to achieve reproducible macroscopic amount of homogeneous samples. Meanwhile, with the growing interest in the process of composing developed materials, nanoscale building blocks are employed.[8] Nanoparticles have attracted the attention of an increasing number of researchers from different disciplines through the past 10 years. The term "nanoparticle" came into common use in the early 1990s along with the relevant concepts, "nanoscales" or "nanosized" particle. Before then, more general terms submicron and ultrafine were used. The term nanoparticle is generally used these days in the material science community to refer to particles with diameters smaller than $100 \mathrm{~nm} .[9]$.

The advantages of ultrasonic technology are as follows: ultrasonication can bring various benefits, such as environmental friendliness (no toxic chemicals are used or produced), cost efficiency, and compact, on-site treatment. [10] 
In another study, the scholars have studies the Synthesis, physical characterization and biological evaluation of Schiff base M(II) complexes, their findings showed that the results exhibit that the synthesized ligand binds with metal ions in tridentate through S,S donor sites of trithiocarbonate as well as $\mathrm{N}$ atom of the azomethine group. Thermogravimetric studies of the complexes also helped to characterize the complexes. The antibacterial data show that the metal complexes have biological activity compared to that of parent ligand [11].

About utilization of this technology in synthesis process, we can refer to a study conducted by Bang and Suslick, in which they believe that the utilization of high intensity ultrasound offers a facile, versatile synthetic tool for nanostructured materials that are often unavailable by conventional methods. They concluded that Ultrasonic irradiation provides unique reaction conditions via acoustic cavitation. Bubbles generated during sonication can effectively accumulate the diffuse energy of ultrasound, and upon collapse, an enormous concentration of energy is released to heat the contents of the bubble [12].

In another study, the biological aspect of Schiff bases was evaluated. The Schiff base and their metal complexes were tested for antimicrobial activity against gram positive bacteria Staphylococcus aureus, Streptococcus pyogenes and gram negative bacteria Escherichia coli, Pseudomonas aeruginosa and fungus Candida albicans, Aspergillus niger and Aspergillus clavatus using Broth Dilution Method [13].

Salavati-Niasari, Fereshteh, and Davar scrutinized the Synthesis of cobalt nanoparticles from [bis(2-hydroxyacetophenato)cobalt(II)] by thermal decomposition. They found that the assynthesized cobalt particles show very good crystallinity and are stable in hexane as solvent against air oxidation. This method is nontoxic, facile and inexpensive. Co nanoparticles have common features of superparamagnetic at room temperature. This work is easily extended to other metals [14].

Saez and Mason, reviewed reviews the nanomaterials that have been prepared to date by pulsed sonoelectrochemistry Pulsed sonoelectrochemistry techniques, which use $20 \mathrm{kHz}$ ultrasound horn both as working electrode and ultrasound emitter, have been used to prepare nanopowders. The majority of nanomaterials produced by this method are pure metals. More recently, the syntheses have been extended to include the preparation of nanosized metallic alloys, metal oxide semiconductors and conductive polymers. Factors, which affect the process yield and particle size, are the ultrasound pulse time and the current density [15].

In this study, by considering that paying attention to have high efficacy of nanoparticles in fields such as catalytsts and antibacterial activity in nano-size scale, with this aim reaching to synthesis of cobalt nano particle, usd cobalt (II) chloride by sonication method. We proof this with scanning electron microscopy (SEM) method. 


\section{Experiment:}

\subsection{Ligand Synthesis:}

For ligand synthesis, 0.001 para-chloro-anilinemol is dissolved in 10 ccof ether solution, then $0.001 \mathrm{~mol} 3$ nitro-benzaldehyde is dissolved in $10 \mathrm{cc}$ of ether solution.

Through the next stage, these two are reacted at room temperature for 15 minutes. The produced precipitate is yellow and ligand is formed with $93 \%$ of efficiency.<smiles>Nc1ccc(Cl)cc1</smiles><smiles>O=Cc1cccc([N+](=O)[O-])c1</smiles>

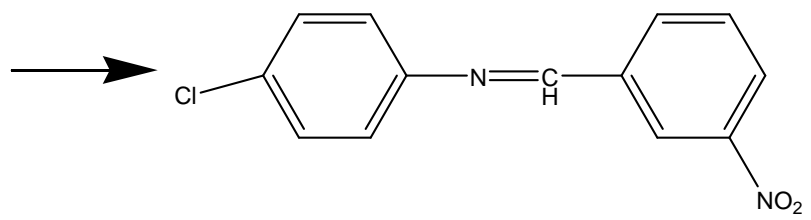

Figure 1: Organic ligand Schiff base formation reaction

Then, $0.001 \mathrm{~mol}$ cobalt (II) chloride is dissolved in diethyl ether solvent and placed in an ultrasonic bath; ligand is added to the metal drop by drop.

Nanoparticle synthesis total time is 9 minutes, which is done in cross-sectional way, with three times intervals. After completely adding ligand to the metal, it is placed in ultrasonic bath three time, each a minute, to let the reaction be performed.

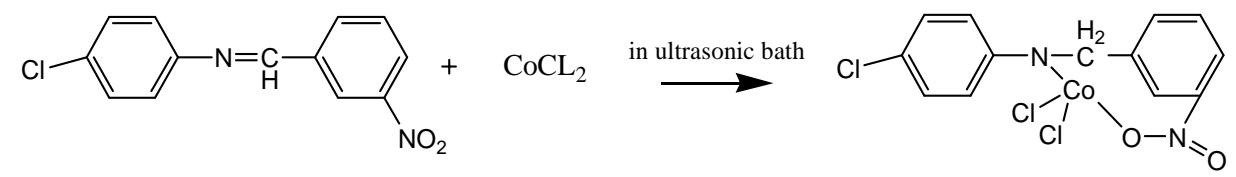

Figure 2: Ligand and CoCL2 reaction in ultrasonic bath 
Bulletin de la Société Royale des Sciences de Liège, Vol. 86, special issue, 2017, p. 182 - 188

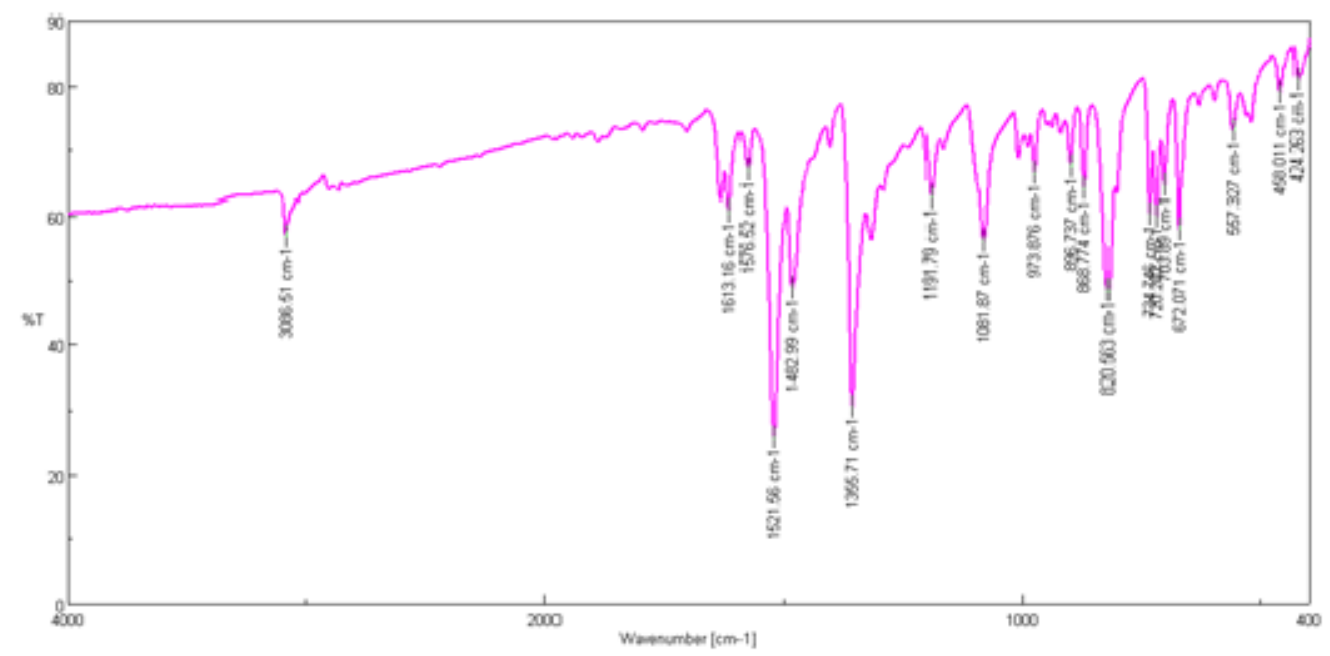

Figure 3: IR spectrum of organic ligand Schiff base

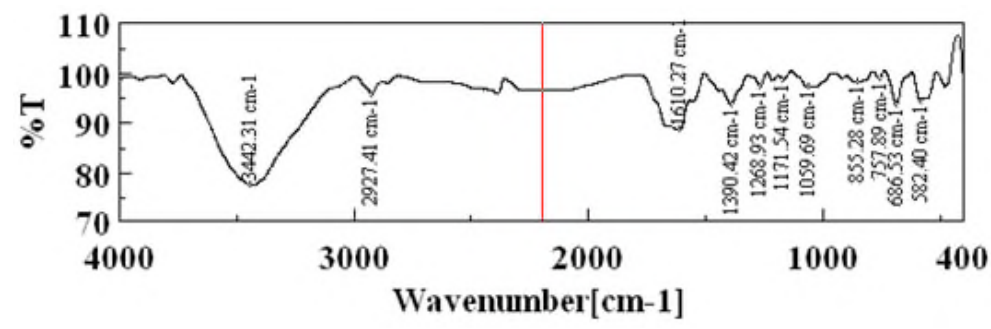

Figure 4: IR spectrum of complex by $\mathrm{Co}(\mathrm{II})$

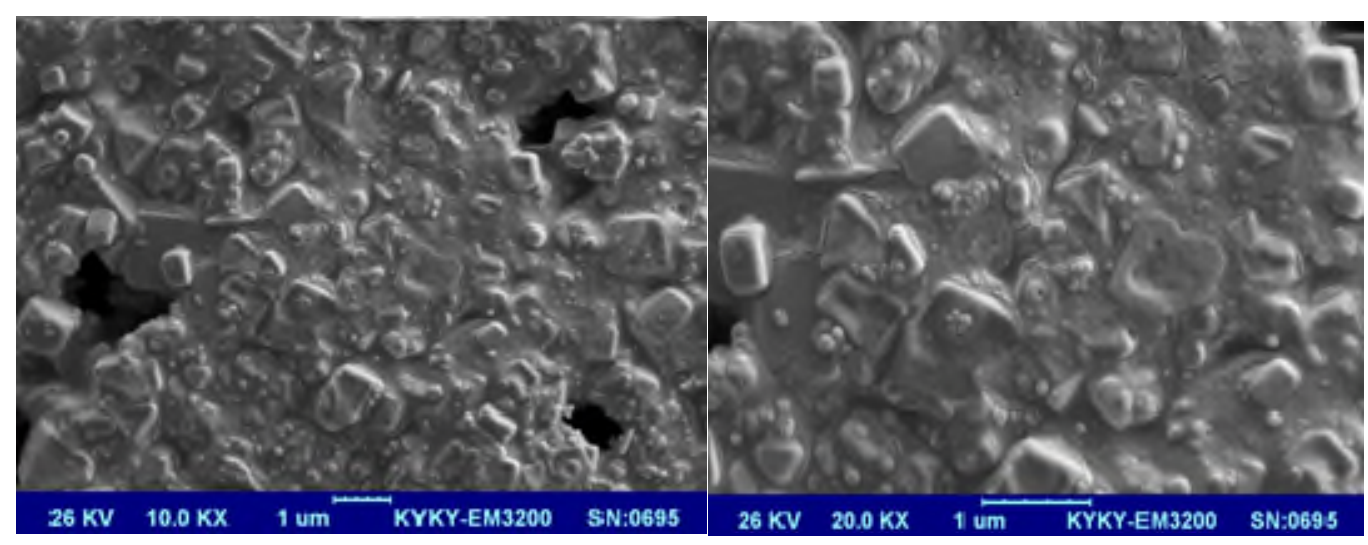


Bulletin de la Société Royale des Sciences de Liège, Vol. 86, special issue, 2017, p. 182 - 188

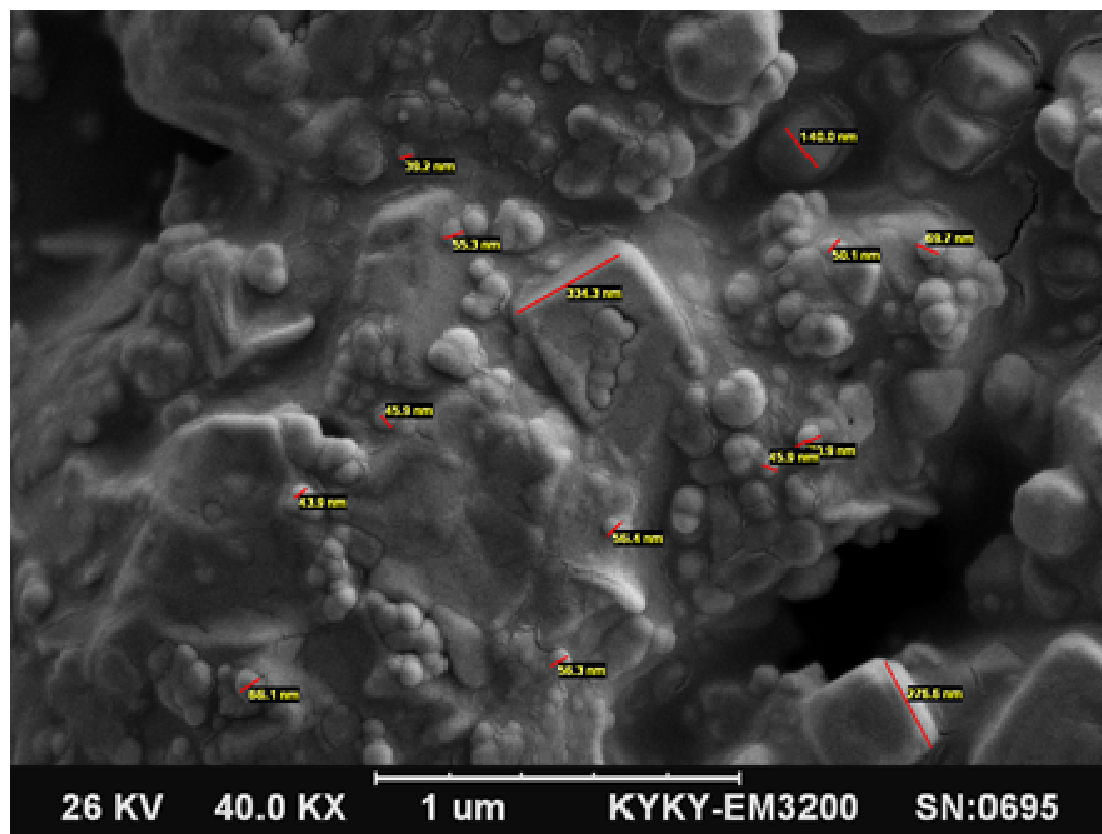

Figure 5: SEM images of nanoparticles

Table 1

\begin{tabular}{|c|c|c|c|}
\hline $\begin{array}{c}\text { Stretching Vibration of } \\
\mathrm{C}=\mathrm{N}\end{array}$ & $\begin{array}{c}\text { Stretching Vibration } \\
\text { of } \mathrm{C}-\mathrm{H}\end{array}$ & $\begin{array}{c}\text { Stretching Vibration of } \\
\mathrm{C}=\mathrm{C}\end{array}$ & $\begin{array}{c}\text { bending Vibration } \\
\text { ofC-H }\end{array}$ \\
\hline $1613 \mathrm{~cm}^{-1}$ & $3086 \mathrm{~cm}^{-1}$ & $1355-1521 \mathrm{~cm}^{-1}$ & $820 \mathrm{~cm}^{-1}$ \\
\hline
\end{tabular}

Table 2

\begin{tabular}{|c|c|c|c|}
\hline $\begin{array}{c}\text { Stretching Vibration of } \\
\mathrm{C}=\mathrm{N}\end{array}$ & $\begin{array}{c}\text { Stretching Vibration } \\
\text { of } \mathrm{C}-\mathrm{H}\end{array}$ & $\begin{array}{c}\text { Stretching Vibration of } \\
\mathrm{C}=\mathrm{C}\end{array}$ & $\begin{array}{c}\text { bending Vibration } \\
\text { ofC-H }\end{array}$ \\
\hline $1610 \mathrm{~cm}^{-1}$ & $3442 \mathrm{~cm}^{-1}$ & $1170-1390 \mathrm{~cm}^{-1}$ & $855 \mathrm{~cm}^{-1}$ \\
\hline
\end{tabular}

\section{Conclusion}

It is clear that reaction between primary amins and aldehydes yield Schiff base. p-chloroaniline and 3-nitro benzaldehyde was used. According to table 1 spectrum mentioned above, $820 \mathrm{~cm}^{-1}$ bonds refer to $\mathrm{C}-\mathrm{H}$ bending frequency, 1521-1355 related to $\mathrm{C}=\mathrm{C}$ benzene bond, 3089 stretching frequency of aromatic $\mathrm{C}-\mathrm{H}$ and $152 \mathrm{C}=\mathrm{N}$. As it is shown in the above results table, IR area confirming $\mathrm{C}=\mathrm{N}$ bond, indicates imine formation which is the same as Schiff base (ligand 
Bulletin de la Société Royale des Sciences de Liège, Vol. 86, special issue, 2017, p. 182 - 188

formation). According to table 2 spectrum shape area 3422 relate to $\mathrm{C}-\mathrm{H}$ bond stretching frequency, $1610 \mathrm{C}=\mathrm{N}$ which conforming imines as well, 1171-1390 are $\mathrm{C}=\mathrm{C}$ bonding , 855 $\mathrm{C}-\mathrm{H}$ bending frequency.Finally, to prove nano-size dimension magnification of scanning electron microscopy (SEM) was used that compered to optical microscopy 100 to 100000 timeds more with resolution of 3 to $100 \mathrm{~nm}$.Dimensions measured by scanning electron microscope (SEM) are reported as to be $43 \mathrm{~nm}, 45 \mathrm{~nm}, 39 \mathrm{~nm}, 50 \mathrm{~nm}$ and $69 \mathrm{~nm}$ respectively. According to the size reported in the table above, nanoscale particles smaller than $100 \mathrm{~m}$, which are theoretically acceptable, are suitable to form the desired nanoparticle.

\section{References}

[1] J.H. Fendler. Atomic and molecular clusters in membrane mimetic chemistry. Chem. Rev. 87 (1987) 877-899.

[2] G. Schmid. Large clusters and colloids. Metals in the embryonic state. Chem. Rev. 92 (1992) 1709-1727.

[3] P.V. Kamat. Photochemistry on nonreactive and reactive (semiconductor) surfaces. Chem. Rev. 93 (1993) 267-300.

[4] L.N. Lewis. Chemical catalysis by colloids and clusters. Chem. Rev. 93 (1993) 2693-2730.

[5] B.C. Gates. Supported Metal Clusters: Synthesis, Structure, and Catalysis. Chem. Rev. 95 (1995) 511-522.

[6] L.L. Beecroft, C.K. Ober. Nanocomposite Materials for Optical Applications. Chem. Mater. 9 (1997) 1302-1317.

[7] N. Toshima, T. Yonezawa, New J. Chem. Bimetallic nanoparticles-novel materials for chemical and physical applications. 1179-1201 (1998).

[8] C.M. Lieber, Solid State Commun. 107 (1998) 607; A.P.

[9] Abeles, B., Pinch, H. L. and Gittleman, J. I. (1975) Percolation conductivity in W-A12 O3 granular metal films.Phys. Rev. ,ett. 35, 247-250.

[10] Sharma, S. K. (2011). Ultrasound Technology in Green Chemistry. New York: Spirnger.

[11] Alias, M., Kassum, H., Shakir, C. (2014). Synthesis, physical characterization and biological evaluation of Schiff base M(II) complexes. Journal of the Association of Arab Universities for Basic and Applied Sciences, 15, 28-34.

[12] Bang, J. H., \& Suslick, K. S. (2010). Applications of Ultrasound to the Synthesis of Nanostructured Materials. Advanced Materials, 22, 1039-1059. 
Bulletin de la Société Royale des Sciences de Liège, Vol. 86, special issue, 2017, p. 182 - 188

[13] Pandya, J. H., Jadeja, R. N., \& Ganatra, K. J. (2011). Spectral characterization and biological evaluation of Schiff bases and their mixed ligand metal complexes derived from 4,6diacetylresorcinol. Journal of Saudi Chemical Society.

[14] Salavati-Niasari, M., Fereshteh, Z., \& Davar, F. (2009). Synthesis of cobalt nanoparticles from [bis(2-hydroxyacetophenato)cobalt(II)] by thermal decomposition. Polyhedron, 28,10651068.

[15] Sáez, V., \& Mason, T. J. (2009). Sonoelectrochemical Synthesis of Nanoparticles. Molecules, 14, 4284-4299. 